\title{
Evaluation of antioxidant activity of extracts from the roots and shoots of Scutellaria alpina L. and S. altissima L. in selected blood cells
}

\author{
Izabela Grzegorczyk-Karolak' ${ }^{1, A-D, F}$, Bogdan Kontek 2,B, Renata Kontek ${ }^{3, A, C, F}$, Halina Wysokińska, , , Beata Olas 2,A,C,F \\ ${ }^{1}$ Department of Biology and Pharmaceutical Botany, Faculty of Pharmacy, Medical University of Lodz, Poland \\ ${ }^{2}$ Department of General Biochemistry, Faculty of Biology and Environmental Protection, University of Lodz, Poland \\ ${ }^{3}$ Laboratory of Cytogenetics, Faculty of Biology and Environmental Protection, University of Lodz, Poland \\ A - research concept and design; B - collection and/or assembly of data; $\mathrm{C}$ - data analysis and interpretation; \\ $D$ - writing the article; $E$ - critical revision of the article; $F$ - final approval of the article
}

\author{
Address for correspondence \\ Izabela Grzegorczyk-Karolak \\ E-mail: izabela.grzegorczyk@umed.lodz.pl \\ Funding sources \\ None declared \\ Conflict of interest \\ None declared

\section{Acknowledgment} \\ Special thanks to Dr. Joanna Ruszkowska \\ (Medical University of Lodz), Mrs. Malwina Borys \\ and the staff of the diagnostic laboratory \\ in Konstantynów Łódzki for technical assistance.
}

Received on April 18, 2017

Reviewed on July 30, 2017

Accepted on October 13, 2017

Published online on August 7, 2018

Cite as

Grzegorczyk-Karolak I, Kontek B, Kontek R, Wysokińska H, Olas B. Evaluation of antioxidant activity of extracts from the roots and shoots of Scutellaria alpina $\mathrm{L}$. and S. altissima $\mathrm{L}$. in selected blood cells. Adv Clin Exp Med. 2019;28(4):453-460. doi:10.17219/acem/78589

DOI

10.17219/acem/78589

\section{Copyright}

Copyright by Author(s)

This is an article distributed under the terms of the

Creative Commons Attribution Non-Commercial License

(http://creativecommons.org/licenses/by-nc-nd/4.0/)

\begin{abstract}
Background. It is widely known that reactive oxygen species (ROS) can cause oxidative damage in cells and have been linked to the pathogenesis of oxidative diseases, such as atherosclerosis, ischemia, neurodegenerative disease, diabetes, or cancer. Recently, much attention has been focused on preventive strategies for oxidative stress and related diseases. Plants represent a source of bioactive compounds whose antioxidant activity may be useful in protecting against pro-oxidative reactions.

Objectives. The study determines the in vitro biological activity of the ethanolic extracts from the shoots and roots of Scutellaria species (S. altissima and S. alpina) in selected blood cells (blood platelets and lymphocytes).

Material and methods. Platelet activity, both resting and after thrombin stimulation, was used to indicate the ability of the plant extracts to inhibit the production of superoxide anion radicals $\left(\mathrm{O}_{2}{ }^{-}\right)$and platelet lipid peroxidation. The generation of superoxide anion radicals was measured with cytochrome c reduction. Lipid peroxidation in blood platelets was measured by the level of thiobarbituric acid reactive substances (TBARS). The 3-(4,5-dimethylthiazol-2-yl)-2,5-diphenyltetrazolium bromide (MTT) colorimetric assay was used to determine the protective effect of Scutellaria extracts on lymphocyte cells against oxidative damage induced by hydroxyl radicals.
\end{abstract}

Results. Extracts $(5-50 \mu \mathrm{g} / \mathrm{mL})$ containing phenolic compounds from both Scutellaria species distinctly reduced nonenzymatic lipid peroxidation and arachidonic acid metabolism by blood platelets in vitro. When given at the tested concentration, the extracts reduced the generation of $\mathrm{O}_{2}^{-}$in resting blood platelets and platelets activated by thrombin in vitro. All Scutellaria extracts $(10 \mu \mathrm{g} / \mathrm{mL})$ containing phenolic compounds also protected human lymphocytes against oxidative stress induced by hydrogen peroxide $\left(\mathrm{H}_{2} \mathrm{O}_{2}\right)$.

Conclusions. The present study suggests that the natural extracts from S. altissima and S. alpina have antioxidant properties and, therefore, may be beneficial in the prevention of diseases in which blood platelets and lymphocytes are involved, i.e., cancer or inflammatory and infective diseases.

Key words: oxidative stress, lymphocytes, blood platelets, polyphenols, Scutellaria 


\section{Introduction}

Reactive oxygen radicals are released under conditions of stress and cause a number of pathological changes in all cells of the human organism. In recent years, increased attention has been given to the antioxidant activity of plants. Many studies suggest that several medicinal plants containing polyphenolic compounds can protect cells against destructive oxidative damage and limit the risk of various diseases associated with oxidative stress. Natural antioxidants are known to be radical scavengers or radical-chain breakers, which can inhibit or delay the oxidation process.

Extracts from Scutellaria plants have been used in traditional Chinese medicine for their hepatoprotective, anti-inflammatory, antihistaminic, hyperlipidemic, antibacterial, antiviral, antitumor, and other pharmacological properties for centuries. ${ }^{1}$ Today it is known that the dominant role in these therapeutic effects may be attributed to their antiradical properties. Flavones present in Scutellaria extracts, which can bind and eliminate heavy metals and scavenge free radicals, are strong antioxidants. Experiments have shown that the flavonoids present in skullcap plants protect hepatocytes against necrosis and mutagenesis induced by toxins, high doses of paracetamol or hydrogen peroxide $\left(\mathrm{H}_{2} \mathrm{O}_{2}\right){ }^{2-4}$ Scutellaria metabolites have demonstrated protective activity towards nervous cells and have effectively limited the development of neurodegenerative diseases. For example, baicalin is known to have a neuroprotective effect against 1-methyl-4-phenyl-1,2,3,6tetrahydropyridine (MPTP), a factor causing changes in dopaminergic neurons, which can translate into the occurrence of the Parkinson's disease. ${ }^{5}$ Scutellaria extracts have also exhibited a protective effect on erythrocytes and prevented their membranes from free radical damage. ${ }^{6}$ However, no studies have examined the effects of skullcap extracts on the viability and function of the other cellular components of blood under conditions of oxidative stress.

Blood platelet activation results in the production of reactive oxygen species (ROS), which play a crucial role in hemostasis and thrombosis. Reactive oxygen species can behave as $2^{\text {nd }}$ messengers during platelet activation and participate in signaling pathways. ${ }^{7}$ Several sources of ROS in blood platelets are postulated, one of which being the metabolites of arachidonic acid. ${ }^{8}$ Under pathological conditions, oxidants generated by activated blood platelets or inflammatory cells may promote oxidative stress and influence platelet functions, which can damage platelet structure. ${ }^{9}$ In fact, one of the therapeutic strategies used in the treatment and prophylaxis of cardiovascular disease is the prevention of platelet activation during exposure to oxidative stress. Another important component of the blood are lymphocytes, which act as the basis of the specific resistance of the organism by initiating the immune response. Lowering their amounts and activity leads to the inhibition of the immune system. ${ }^{10}$
Previously, we have demonstrated the antioxidant properties of Scutellaria extract in human blood plasma. ${ }^{11}$ The aim of the paper is to determine the in vitro protective effect of ethanolic extracts, derived from the shoots and roots of Scutellaria altissima and S. alpina, on blood platelets and lymphocytes. The aim of the study was to investigate the antioxidant activity of skullcap extracts against the effect of a strong biological oxidant, $\mathrm{H}_{2} \mathrm{O}_{2}$, a known hydroxyl radical donor, on human lymphocytes. The study also examines the effect of Scutellaria extract on lipid peroxidation, and on superoxide anion $\left(\mathrm{O}_{2}{ }^{--}\right)$production in resting blood platelets and platelets activated by thrombin, a strong physiological agonist. Experimental models used in this study are similar to reactions which take place in human cells under conditions of oxidative stress or during blood platelet activation.

\section{Material and methods}

\section{Plant material}

The roots and aerial parts of S. altissima L. and S. alpina L. were used for the study. The plants had previously been growing for 2 years under field conditions in the Medical Plant Garden of the Department of Pharmacognosy, Medical University of Lodz, Poland. The plants were identified on the basis of the Flora Europaea by I. GrzegorczykKarolak and voucher specimens were deposited in Department of Biology and Pharmaceutical Botany, Medical University of Lodz, Poland. ${ }^{12}$

\section{Preparation of extracts}

The lyophilized plant material (1 g) was pre-extracted with chloroform overnight. After filtration, the plant material was extracted 3 times in a $30 \mathrm{~mL}$ ethanol-water (7:3) mixture for $15 \mathrm{~min}$ in an ultrasonic bath. The extracts were combined and evaporated under reduced pressure.

\section{Total phenolic determination}

Total phenolic content was measured using the FolinCiocalteu method as described by Singleton and Rossi. ${ }^{13}$ Briefly, $400 \mu \mathrm{L}$ of each extract was mixed with $2 \mathrm{~mL}$ of Folin-Ciocalteu reagent (diluted 10-fold) and $1.6 \mathrm{~mL}$ of $7.5 \%$ sodium carbonate $\left(\mathrm{Na}_{2} \mathrm{CO}_{3}\right)$. The absorbance was determined by spectrophotometry at $765 \mathrm{~nm}$ (Beijing Rayleigh Corp., Beijing, China) after 30 min of incubation at room temperature. The results were expressed as mg gallic acid equivalents (GAE) per gram of dry extract. The calibration curve was obtained by preparing a gallic acid solution in the concentration range $1-400 \mathrm{mg} / \mathrm{mL}$. The results are mean values of 9 independent experiments. 


\section{Blood platelet isolation}

Peripheral blood was collected from 5 non-smoking volunteers into ACD solution (citric acid/citrate/dextrose; 5:1; v/v; blood/ACD). Donors were healthy men and women aged 35-45 years, with normal body mass (body mass index [BMI] between 22 and 25). They did not take any medications or addictive substances, including tobacco, alcohol, antioxidant supplementation, aspirin, or any other anti-platelet drugs. They did not take treatment for any kind of systemic disease in their histories. The protocol was approved by the Committee for Research on $\mathrm{Hu}$ man Subjects, University of Lodz, Poland (reference: 2/KBBN-UŁ/III/2014). Platelet-rich plasma (PRP) was prepared by centrifugation of fresh human blood at $250 \times \mathrm{g}$ for $10 \mathrm{~min}$ at room temperature. Platelets were then sedimented by centrifugation at $500 \times \mathrm{g}$ for $10 \mathrm{~min}$ at room temperature. The platelet pellet was washed twice with Tyrode's buffer containing $10 \mathrm{mM}$ 4-(2-hydroxyethyl)1-piperazineethanesulfonic acid (HEPES), $140 \mathrm{mM}$ sodium chloride $(\mathrm{NaCl}), 3 \mathrm{mM}$ potassium chloride $(\mathrm{KCl})$, $0.5 \mathrm{mM}$ magnesium chloride $\left(\mathrm{MgCl}_{2}\right), 5 \mathrm{mM}$ sodium bicarbonate $\left(\mathrm{NaHCO}_{3}\right)$, and $10 \mathrm{mM}$ glucose $(\mathrm{pH} 7.4)$, and the platelets were suspended in Tyrode's buffer. Spectrophotometric evaluation found the concentration of platelets in platelet suspensions to be about $5 \times 10^{8} / \mathrm{mL} .{ }^{14}$ The suspensions of blood platelets were incubated with plant extracts at final concentrations of $0.5-50 \mu \mathrm{g} / \mathrm{mL}$ $\left(15 \mathrm{~min}\right.$, at $\left.37^{\circ} \mathrm{C}\right)$, with or without the addition of thrombin $\left(5 \mathrm{U} / \mathrm{mL}, 5 \mathrm{~min}, 37^{\circ} \mathrm{C}\right)$.

\section{Superoxide anion radical measurement}

The generation of $\mathrm{O}_{2}{ }^{-}$in the control platelets and in platelets incubated with tested extracts was measured by an inhibitable reduction of cytochrome c using superoxide dismutase $(1 \mu \mathrm{g} / \mathrm{mL})$, as described earlier. ${ }^{15}$ Briefly, an equal volume of modified Tyrode's buffer containing cytochrome c $(160 \mu \mathrm{M})$ (Sigma-Aldrich, St. Louis, USA) was added to a platelet suspension. After incubation, the platelets were sedimented by centrifugation at 2,000 $\times$ g for $5 \mathrm{~min}$ and the supernatants were transferred to cuvettes. Any reduction in cytochrome c was measured spectrophotometrically at $550 \mathrm{~nm}$. To calculate the molar concentration of $\mathrm{O}_{2}^{--}$, the molar extinction coefficient for cytochrome $\mathrm{c}$ was taken as $18,700 / \mathrm{M} \times \mathrm{cm}$.

\section{Lipid peroxidation measurement}

Lipid peroxidation was quantified by measuring the concentration of thiobarbituric acid reactive substances (TBARS) (Sigma-Aldrich). Incubation of platelets was stopped by cooling the samples in an ice bath. Samples of platelets were transferred to an equal volume of $20 \%$ (v/v) cold trichloroacetic acid in $0.6 \mathrm{M} \mathrm{HCl}$ and centrifuged at $1,200 \times \mathrm{g}$ for $15 \mathrm{~min}$. The clear supernatant was mixed with $0.12 \mathrm{M}$ thiobarbituric acid in $0.26 \mathrm{M}$ Tris at $\mathrm{pH} 7.0$ in a ratio of $5: 1$ by volume and immersed in a boiling water bath for $15 \mathrm{~min}$. Absorbance was measured at $532 \mathrm{~nm}$ (Spectrophotometer UV/Vis Helios alpha; Unicam, Cambridge, UK). ${ }^{16}$ The TBARS concentration was calculated using the molar extinction coefficient $(\varepsilon=15,600 / \mathrm{M} \times \mathrm{cm})$.

\section{Lymphocyte cultures}

Lymphocytes were isolated from peripheral human blood obtained from medication-free, regular nonsmoking donors at the blood bank (Łódź, Poland) by centrifugation in a density gradient with Histopaque 1077 (Sigma-Aldrich) at $300 \times \mathrm{g}$ for $15 \mathrm{~min}$. The protocol was approved by the Committee for Research on $\mathrm{Hu}$ man Subjects, University of Lodz, Poland (reference No.: 2/KBBN-UŁ/III/2014). The cells were suspended in Roswell Park Memorial Institute (RPMI) 1640 culture medium with Glutamax, 15\% inactivated fetal bovine serum (FBS), 1\% penicillin and streptomycin, and 1\% mitogen PHA (added $24 \mathrm{~h}$ before application of the tested compound). The lymphocytes were incubated at $37^{\circ} \mathrm{C}$ in a humidified atmosphere of $95 \%$ air and $5 \% \mathrm{CO}_{2}$.

\section{3-(4,5-dimethylthiazol-2-yl)-2,5- -diphenyltetrazolium bromide assay}

Lymphocyte viability was determined by 3-(4,5-dimethylthiazol-2-yl)-2,5-diphenyltetrazolium bromide (MTT) assay. ${ }^{17}$ The MTT test is based on the reduction of tetrazolium to colored formazan by dehydrogenase inside living cells. The assay only detects living cells and the signal generated is dependent on their degree of activation. A 24-hour culture of lymphocytes seeded on to 96-well microplates at $10^{3}$ cells/well was treated with extracts of shoot and root S. altissima and S. alpina at a concentration of $10 \mu \mathrm{g} / \mathrm{mL}$. Fifteen min before the end of the incubation period, $\mathrm{H}_{2} \mathrm{O}_{2}$ solutions at concentrations of 0.1 , $0.5,1$ or $1.5 \mathrm{mM}$ were added to the wells. After this time, $20 \mu \mathrm{L}$ of fresh MTT solution, i.e., $5 \mathrm{mg} / \mathrm{mL} \mathrm{MTT}$ in sterile phosphate-buffered saline (PBS), was added to each well and the plates were incubated for the next $3 \mathrm{~h}$. Following this, a $100 \mu \mathrm{L}$ mixture of $20 \%$ sodium dodecyl sulfate (SDS) and $50 \%$ dimethylformamide (DMF) was added to each well and left for $24 \mathrm{~h}$. The absorbance of purple formazan solution was measured spectrophotometrically using a microplate reader (BioTek Instruments Inc., Winooski, USA) at $595 \mathrm{~nm}$. A lymphocyte culture treated with $\mathrm{H}_{2} \mathrm{O}_{2}$, but without any plant extracts, was used as a positive control, while a culture of cells not exposed to any of the tested compounds was used as a negative control. Any observed reduction of MTT after treatment with the tested compounds was compared to the negative control, which represented a $100 \%$ MTT reduction. ${ }^{18}$ All results were presented as the means of the replicates from 6 independent experiments. 


\section{Data analysis}

Several tests were used in the statistical analysis. In order to eliminate uncertain data, Dixon's Q test was performed. Significant differences were assessed with the Kruskal-Wallis test. Differences were considered significant at $\mathrm{p}<0.05$. All the values in this study were expressed as mean \pm standard error (SE). The statistical analysis was performed with STATISTICA v. 10.0 software (StatSoft Inc., Tulsa, USA).

\section{Results}

We have observed that Scutellaria extracts may decrease the oxidative alteration of lipids and the level of ROS in both resting blood platelets and those activated by thrombin. However, the exposure of blood platelets to thrombin $(5 \mathrm{U} / \mathrm{mL})$ resulted in stronger oxidative changes than observed in the resting blood platelets (controls). Thrombin, which is a known effective inducer of platelet activation, increased both $\mathrm{O}_{2}{ }^{--}$production $\left(2.26 \mathrm{nM}\right.$ of $\mathrm{O}_{2}{ }^{--} / 10^{8}$ of platelets vs $1.6 \mathrm{nM}$ of $\mathrm{O}_{2}{ }^{--} / 10^{8}$ of platelet) and lipid peroxidation $(0.7 \mathrm{nM} / \mathrm{mL}$ of platelets vs $0.49 \mathrm{nM} / \mathrm{mL}$ of platelets).

Cytochrome c reduction was used to test the ability of analyzed extracts to influence ROS generation in platelets. Extracts from the shoots and roots of S. altissima and S. alpina at concentrations of $0.5-50 \mu \mathrm{g} / \mathrm{mL}$ decreased the production of $\mathrm{O}_{2}^{--}$in resting blood platelets and those activated by thrombin in vitro in a dose-dependent manner (Fig. 1). Root and shoot extracts from both species had similar inhibitory effects at the same concentrations. The highest dose of skullcap extracts reduced $\mathrm{O}_{2}{ }^{--}$production in platelets by about $30 \%$ (Table 1). The Scutellaria extracts were also observed to bestow a protective effect at lower concentrations $(5 \mu \mathrm{g} / \mathrm{mL})$; however, only slight inhibition of $\mathrm{O}_{2}{ }^{--}$generation was observed at the lowest concentration $(0.5 \mu \mathrm{g} / \mathrm{mL})$.

The TBARS level was measured as nonenzymatic lipid peroxidation in resting blood platelets and as enzymatic lipid peroxidation of arachidonic acid in blood platelets stimulated by thrombin. The tested extracts decreased

Table 1. Inhibitory effects of extracts from shoots and roots of Scutellaria altissima and S. alpina (50 $\mathrm{gg} / \mathrm{mL} ; 15 \mathrm{~min}$ ) on the production of $\mathrm{O}_{2}{ }^{-}$in blood platelets

\begin{tabular}{|c|c|c|}
\hline Plant material & $\begin{array}{l}\text { Inhibition } \\
\text { of the production } \\
\text { of } \mathrm{O}_{2}^{--} \text {in resting } \\
\text { blood platelets [\%] }\end{array}$ & $\begin{array}{l}\text { Inhibition } \\
\text { of the production } \\
\text { of } \mathrm{O}_{2}^{--} \text {in blood } \\
\text { platelets activated } \\
\text { by thrombin [\%] }\end{array}$ \\
\hline S. altissima shoots & $35.4 \pm 6.07^{a}$ & $32.9 \pm 2.93^{\mathrm{a}}$ \\
\hline S. altissima roots & $35.3 \pm 3.96^{a}$ & $34.6 \pm 2.29^{a}$ \\
\hline S. alpina shoots & $33.3 \pm 4.01^{a}$ & $33.3 \pm 2.34^{a}$ \\
\hline S. alpina roots & $33.0 \pm 4.26^{a}$ & $32.7 \pm 2.74^{\mathrm{a}}$ \\
\hline
\end{tabular}

The results are mean values \pm standard error (SE) of 3 replicates for each of the 5 donors. Means with the same letters for the same column are not significant according to the Kruskal-Wallis test at $p<0.05$.
A

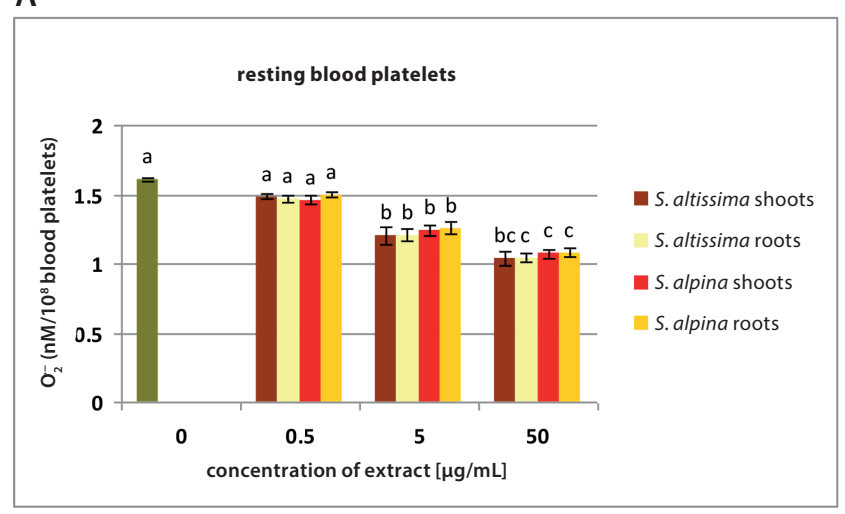

B

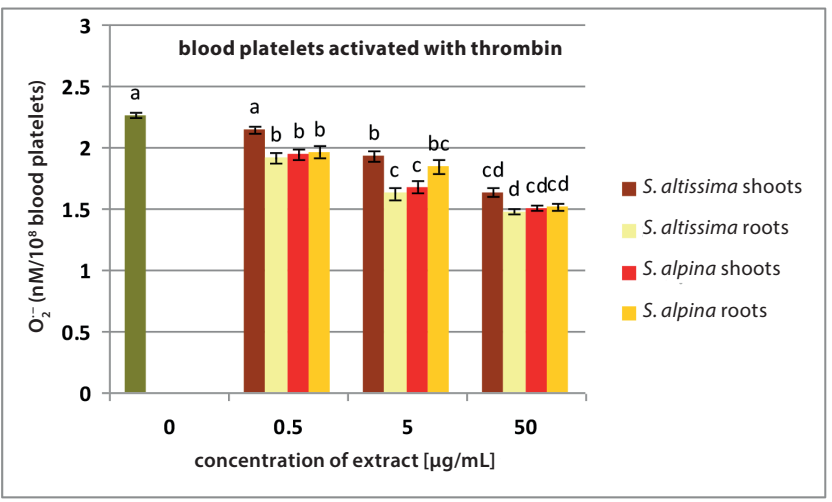

Fig. 1. The effects of shoot and root extracts of Scutellaria altissima and S. alpina $\left(0.5-50 \mathrm{\mu g} / \mathrm{mL} ; 15 \mathrm{~min}, 37^{\circ} \mathrm{C}\right)$ on $\mathrm{O}_{2}{ }^{-}$- generation in resting blood platelets (A) and blood platelets activated by thrombin $(5 \mathrm{U} / \mathrm{mL}, 5 \mathrm{~min}$, $37^{\circ} \mathrm{C}$ ) (B). The data represents means of 3 replicates for each of the 5 donors \pm standard error (SE). Means with the same letters for treatment (resting blood platelets or blood platelets activated by thrombin) are not significant according to the Kruskal-Wallis test at $p<0.05$

TBARS level. After a 15-minute pre-incubation of blood platelets with both shoot and root extracts of $S$. altissima and $S$. alpina at tested concentrations $(0.5-50 \mu \mathrm{g} / \mathrm{mL})$, the amount of TBARS in resting platelets and thrombinactivated blood platelets was seen to diminish. The activity of the 4 tested extracts was concentration-dependent (Fig. 2). Differences were found between resting platelets and induced platelets regarding lipid peroxidation. In the presence of the highest extract concentrations $(50 \mu \mathrm{g} / \mathrm{mL})$, TBARS production in activated platelets was reduced by about $43 \%$ in the shoot extract of $S$. altissima and about $40 \%$ in the root extract of S. altissima (Table 2). The tested extracts demonstrated less effective antioxidant action regarding the protection of the resting blood platelet lipids; extracts at a concentration of $50 \mu \mathrm{g} / \mathrm{mL}$ inhibited the peroxidation of $22-27 \%$. Even the lowest concentration of the tested extracts $(5 \mu \mathrm{g} / \mathrm{mL})$ was able to reduce TBARS production by about $20 \%$ in activated platelets. In control experiments, dimethyl sulfoxide (DMSO) (the solvent) added to platelet suspensions at a final concentration below $0.05 \%$ did not influence platelet activation in the studied assays. 
Table 2. Inhibitory effects of extracts from shoots and roots of Scutellaria altissima and S. alpina (50 $\mu \mathrm{g} / \mathrm{mL} ; 15 \mathrm{~min})$ on blood platelet lipid peroxidation

\begin{tabular}{|l|c|c|}
\multicolumn{1}{|c|}{ Plant material } & $\begin{array}{c}\text { Inhibition of lipid } \\
\text { peroxidation } \\
\text { in resting blood } \\
\text { platelets [\%] }\end{array}$ & $\begin{array}{c}\text { Inhibition of lipid } \\
\text { peroxidation in blood } \\
\text { platelets activated } \\
\text { by thrombin [\%] }\end{array}$ \\
\hline S. altissima shoots & $21.5 \pm 2.03^{\mathrm{a}}$ & $43.2 \pm 4.39^{\mathrm{a}}$ \\
\hline S. altissima roots & $21.3 \pm 2.96^{\mathrm{a}}$ & $40.6 \pm 3.44^{\mathrm{a}}$ \\
\hline S. alpina shoots & $23.6 \pm 2.87^{\mathrm{a}}$ & $40.3 \pm 3.44^{\mathrm{a}}$ \\
\hline S. alpina roots & $27.4 \pm 3.25^{\mathrm{a}}$ & $40.5 \pm 3.38^{\mathrm{a}}$ \\
\hline
\end{tabular}

The results are mean values \pm standard error (SE) of 3 replicates for each of the 5 donors. Means with the same letters are not significant according to the Kruskal-Wallis test at $\mathrm{p}<0.05$

\section{A}

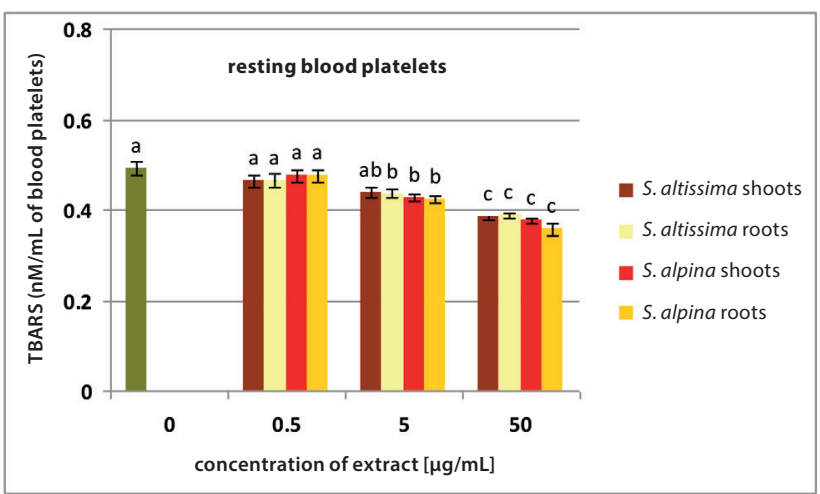

B

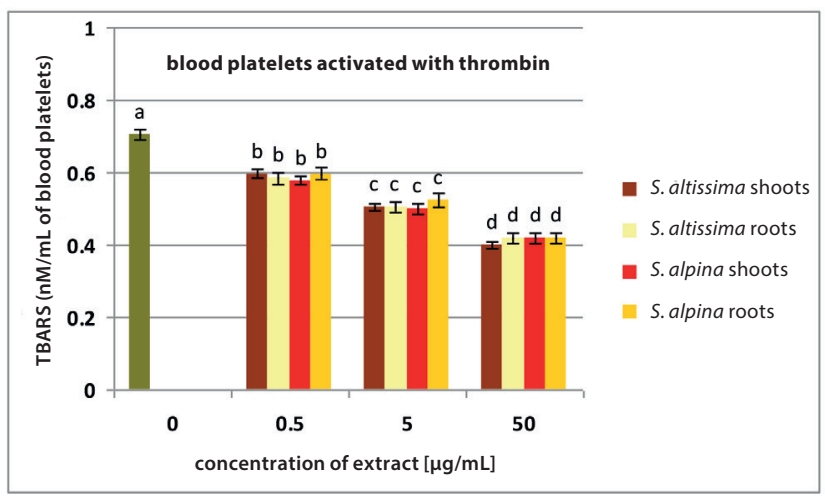

Fig. 2. The effects of shoot and root extracts of Scutellaria altissima and S. alpina $\left(0.5-50 \mu \mathrm{g} / \mathrm{mL} ; 15 \mathrm{~min}, 37^{\circ} \mathrm{C}\right)$ on the level of thiobarbituric acid reactive substances (TBARS) in resting blood platelets $(A)$ and blood platelets activated by thrombin $\left(5 \mathrm{U} / \mathrm{mL}, 5 \mathrm{~min}, 37^{\circ} \mathrm{C}\right)(\mathrm{B})$. The data represents the means of 3 replicates for each of the 5 donors \pm standard error (SE). Means with the same letters for treatment (resting blood platelets or blood platelets activated by thrombin) are not significant according to the Kruskal-Wallis test at $p<0.05$

The results of lymphocyte survival assessment after the treatment with tested plant extracts in the absence and in the presence of $\mathrm{H}_{2} \mathrm{O}_{2}$ are presented in Table 3 . Only the lowest concentration of $\mathrm{H}_{2} \mathrm{O}_{2}(0.1 \mathrm{mM})$ had no significant effect on lymphocyte survival rate. Higher concentrations $(0.5-1.5 \mathrm{mM})$ induced oxidative damage in the lymphocytes resulting in a $40 \%$ decrease in cell viability (Table 3). The results of the MTT assay found that all Scutellaria extracts at concentration of $10 \mu \mathrm{g} / \mathrm{mL}$ increased the viability of the human lymphocyte cells and protected them against damage induced by $\mathrm{H}_{2} \mathrm{O}_{2}$. No significant difference was found in this regard between the plant species or organ used for preparing the extract. In the presence of plant extracts, lymphocyte survival ranged from 90.2 to $98.7 \%$, which was close to that demonstrated by cells grown without stress conditions. Dimethyl sulfoxide added to lymphocyte culture at the concentration used in the study (0.05\%) did not result in any decrease in the survival rate of lymphocytes.

The main group of bioactive compounds found in Scutellaria extracts includes polyphenols such as flavonoids and phenylethanoids. ${ }^{1}$ Both analyzed species have been found to contain flavonoids such as baicalin, wogonoside, luteolin, and cynaroside, as well as the phenylethanoid verbascoside. ${ }^{11}$ Total polyphenol levels in $S$. altissima roots and shoots (30.51 \pm 0.32 and $30.52 \pm 0.09 \mathrm{mg} \mathrm{GAE} / \mathrm{g}$ dry weight of extract, respectively) were found to be $30 \%$ lower than those identified in the $S$. alpina extracts (49.76 \pm 0.52 and $44.55 \pm 0.16 \mathrm{mg} \mathrm{GAE} / \mathrm{g}$ dry weight of extract, respectively).

\section{Discussion}

Recently, much attention has been focused on plants containing various bioactive compounds which may have pharmacological properties, such as antioxidant activity. The present study uses lymphocytes, cells important for the immune system, and blood platelets, which are not only important components of hemostasis or the pathomechanisms of several arterial diseases, but also participate in tumor progression and allergic inflammation. ${ }^{9}$

Blood platelet activation can be strongly induced by thrombin, a proteolytic enzyme and platelet physiological agonist. Thrombin activates platelets by several independent and interactive signal transduction pathways. ${ }^{9}$ Our findings confirm that thrombin stimulates $\mathrm{O}_{2}{ }^{--}$formation and TBARS production in blood platelets (Fig. 1,2). A signal is transmitted into the cell that invokes various biochemical events, including ROS production. This signal also exerts an influence on arachidonic acid metabolism. The ensuing multistage reactions in the cyclooxygenase pathway involve the activation of phospholipase $A_{2}$, which catalyzes the cleavage of arachidonic acid from membrane phospholipids. Free arachidonic acid in platelets is converted mainly to thromboxane $\mathrm{A}_{2}$ ( $\mathrm{TXA}_{2}$ ) and malonyldialdehyde (MDA). ${ }^{19}$ Thromboxane $\mathrm{A}_{2}$ acts as a signaling molecule ( $2^{\text {nd }}$ messengers) in the regulation of blood platelet activation and thrombus formation.

A significant finding of this study is that extracts from shoots and roots of S. altissima and S. alpina inhibit the peroxidation of arachidonic acid and ROS generation in blood platelets by enzymatic and nonenzymatic means, 
Table 3. The effect of extracts from shoots and roots of Scutellaria altissima and S. alpina $(10 \mu \mathrm{g} / \mathrm{mL})$ in the presence of different concentration of hydrogen peroxide $\left(\mathrm{H}_{2} \mathrm{O}_{2}\right)$ on lymphocyte growth after 24-hour incubation evaluated with MTT assay

\begin{tabular}{|l|c|c|c|c|c|}
\hline \multirow{2}{*}{$\begin{array}{c}\text { Concentration } \\
\text { of } \mathrm{H}_{2} \mathrm{O}_{2}[\mathrm{mM}]\end{array}$} & \multicolumn{5}{|c|}{ \% lymphocytes survival } \\
\cline { 2 - 6 } 0 (control) & $\mathrm{H}_{2} \mathrm{O}_{2}$ & S. altissima shoots & S. altissima roots & S. alpina shoots & S. alpina roots \\
\hline 0.1 & $100 \pm 5.16^{\mathrm{a}}$ & $100 \pm 2.00^{\mathrm{a}}$ & $100 \pm 3.02^{\mathrm{a}}$ & $100 \pm 2.35^{\mathrm{a}}$ & $100 \pm 1.62^{\mathrm{a}}$ \\
\hline 0.5 & $97.08 \pm 4.62^{\mathrm{a}}$ & $97.54 \pm 3.18^{\mathrm{a}}$ & $97.88 \pm 1.02^{\mathrm{a}}$ & $97.57 \pm 2.25^{\mathrm{a}}$ & $93.91 \pm 2.43^{\mathrm{a}}$ \\
\hline 1 & $63.66 \pm 1.71^{\mathrm{b}}$ & $94.53 \pm 2.42^{\mathrm{a}}$ & $94.08 \pm 2.87^{\mathrm{a}}$ & $98.51 \pm 2.05^{\mathrm{a}}$ & $91.46 \pm 1.97^{\mathrm{a}}$ \\
\hline 1.5 & $59.92 \pm 2.23^{\mathrm{b}}$ & $94.41 \pm 3.45^{\mathrm{a}}$ & $93.33 \pm 2.54^{\mathrm{a}}$ & $97.79 \pm 2.01^{\mathrm{a}}$ & $91.46 \pm 1.97^{\mathrm{a}}$ \\
\hline
\end{tabular}

The results are mean values \pm standard error (SE) of 3 replicates for each of the 6 samples. Means with the same letters are not significant according to the Kruskal-Wallis test at $p<0.05$

which implies that the tested extracts may inhibit cyclooxygenase activity in platelets. However, $\mathrm{O}_{2}{ }^{--}$generation was also observed in resting platelets. Wachowicz et al. suggested that radical production can be partially associated with glutathione metabolism, or that platelet isolation and resuspension may also stimulate their activation. ${ }^{20}$

The antiplatelet properties of Scutellaria species have only been partly recognized so far. Lee et al. report that a herbal extract named Soshiho-tang containing Scutellaria baicalensis Georgi root demonstrated an anti-thrombotic effect via antiplatelet activity. ${ }^{21} \mathrm{Scu}$ tellaria baicalensis flavonoids are also known to inhibit platelet aggregation, demonstrating an inhibition rate of $45.5 \%$ in 1 study, which was close to the value of $55 \%$ noted for the control group based on aspirin. ${ }^{22}$ The present study found that $S$. alpina extracts were able to reduce $\mathrm{O}_{2} \cdot-$ production in platelets activated by thrombin by $33 \%$, and reduce TBARS production in activated platelets by about $40 \%$. Inhibition of lipid peroxidation, measured by the level of TBARS in blood platelets treated with $\mathrm{ONOO}^{-}$, by Aronia melanocarpa (Michx.) Elliott, a species known for its strong antioxidant properties, was about $30 \% .^{23}$ Vitamin $\mathrm{C}$ at a concentration of $1 \mathrm{mM}$ was found to have comparable activity, inhibiting TBARS production in pig resting blood platelets by about $30 \%{ }^{24}$

The pharmacological properties of the Scutellaria plants are mainly due to the presence of polyphenolic compounds, among them flavonoids, in the plant extracts. Some studies have shown that flavonoids such as baicalin, baicalein, wogonin, or luteolin exhibited generally antioxidant activity, but little research has addressed the antiplatelet properties of the flavonoids. ${ }^{1}$ Kubo et al. report that baicalein, baicalin, wogonin, or wogonoside inhibits the platelet aggregation induced by arachidonic acid by $48 \%$, 31\%, $46 \%$, and $20 \%$, respectively, at a concentration of $1 \mathrm{mM} .^{25}$ In comparison, the positive control, aspirin, inhibited aggregation by $30 \%$. At a concentration of $0.5 \mathrm{mM}$, baicalein and baicalin also inhibited thrombin-induced conversion of fibrinogen to fibrin, slowing it from $193 \mathrm{~s}$ for controls to $413 \mathrm{~s}$ for baicalein and $478 \mathrm{~s}$ for baicalin. Incubation of fibrinogen with heparin $(10 \mathrm{U} / \mathrm{mL})$ prolonged the clotting time only to $281 \mathrm{~s}$.
The $2^{\text {nd }}$ blood cell type used in the present study, the lymphocytes, are an important part of the human immune defense against infection and cancer. When their functioning is disturbed, their activity can be wrongly directed against healthy human tissue, resulting in autoimmune disease. ${ }^{10}$ The results of the MTT assay in the present study found Scutellaria extracts to have a protective effect against oxidative damage induced by a strong biological oxidant, $\mathrm{H}_{2} \mathrm{O}_{2}$, in lymphocyte cells. In previous studies, Zhang et al. found the aqueous extract of $S$. baicalensis to have protective effects at concentrations of 50 and $100 \mu \mathrm{g} / \mathrm{mL}$ against acroleininduced oxidative stress in cultured human umbilical vein endothelial cells. ${ }^{26}$ Shojaee et al. described the protective effects of Scutellaria litwinowii Bornm \& Sint. ex Bornm. root extract against $\mathrm{H}_{2} \mathrm{O}_{2}$-induced DNA changes in normal fibroblasts (NIH/3T3 cell line); however, their MTT and comet assay results suggest that the methanolic S. litwinowii extract demonstrated a protective effect against DNA damage caused by $\mathrm{H}_{2} \mathrm{O}_{2}$ only at high extract concentrations $(1,000 \mu \mathrm{g} / \mathrm{mL}){ }^{27}$

Although this is the first report to describe the effect of S. altissima and S. alpina extracts on lymphocyte oxidative damage, some other authors have reported that other plant species and their metabolites have a protective effect against toxic and mutagenic factors. Porrini and Riso used $\mathrm{H}_{2} \mathrm{O}_{2}$ at a concentration of $0.5 \mathrm{mM}$ to stimulate oxidative stress damage in lymphocytes. ${ }^{28}$ According the authors, the blood cells are excellent markers of the body state and could be a reliable model for studying the effect of the dietary supplementation with antioxidants on the responses of the body to factors causing oxidative stress. In the study, tomato products offered significant protection to lymphocytes against oxidative stress. Lycopene, the main carotenoid isolated from tomatoes, characterized by a great ability to quench singlet oxygen, effectively protected blood lymphocytes from $\mathrm{NO}_{2}$ radical damage. ${ }^{29}$ Elsewhere, Lin et al. examined the protective effects of several plant species extracts against DNA damage in lymphocytes induced by means of $\mathrm{H}_{2} \mathrm{O}_{2} \cdot{ }^{30}$ They report that the inhibition of DNA changes in the presence of tested plants ranged from $74.51 \%$ for Bidens alba (L.) DC. to $91.45 \%$ for Mentha arvensis L. extract at a concentration of $25 \mu \mathrm{g} / \mathrm{mL}$. 
Pool-Zobel et al., using the comet assay, found a significant decrease in endogenous levels of strand breaks in lymphocyte DNA after the intake of tomato juice containing $40 \mathrm{mg}$ lycopene, carrot with $38 \mathrm{mg}$ carotene, or spinach containing 11.3 mg lutein. ${ }^{31}$ Meanwhile, American ginseng extract was effective in protecting human peripheral lymphocytes against radiation-induced oxidative stress. ${ }^{32}$

In the present study, a spectrophotometric method was used to determine the total phenol content in the tested plant extracts. ${ }^{13}$ It has been previously demonstrated that the polyphenol content of Scutellaria extracts was significantly correlated with the antioxidant properties estimated by ferric reducing antioxidant power (FRAP), 2,2-diphenyl-1-picrylhydrazyl (DPPH) and lipid hydroperoxide (LPO) assays. ${ }^{33}$ The findings suggest that the polyphenol compounds were the main contributors to the antioxidant properties of the extract, which is consistent with the findings of many other authors. ${ }^{34,35}$ Our present findings indicate that all tested extracts exhibited similar activity in blood platelets and lymphocytes, although higher levels of polyphenolic compounds were found in S. alpina than $S$. altissima extracts. Also, $M$. arvensis extract was more effective against $\mathrm{H}_{2} \mathrm{O}_{2}$-induced DNA damage in lymphocyte cells than Centella asiatica L. extract, despite the lower content of bioactive compounds (respectively, 21.2 and $32.0 \mathrm{mg}$ gallic acid/g dry weight). ${ }^{30}$ The authors suggested that this could be connected with the synergism present among antioxidant compounds, indicating that the properties of the mixture are dependent not only on the concentrations of the antioxidants, but also on their type and the interaction between them.

The unclear relationship between the protective activity of S. altissima and S. alpina extracts on blood cells and the flavonoid content could also be connected with other factors. The scientific interest in pharmacological activity of Scutellaria plants has been focused mainly on the effects of their flavonoid compounds, but other groups of compounds, for example diterpenoids, could also act as antioxidant and antiplatelet compounds. Several compounds of this group have been described as having antioxidant effects, for example royleanonic acid, tanshinones or carnosol. ${ }^{36-38}$ Diterpenoids have been identified in both S. altissima and S. alpina; however, the plants contain different diterpenoids, whose levels have not yet been evaluated in detail. ${ }^{39,40}$ These differences could account for the results observed in the present study.

\section{Conclusions}

A significant finding of this paper is that it describes the antioxidant properties of polyphenol-rich Scutellaria extracts. When added at a concentration of $10 \mu \mathrm{g} / \mathrm{mL}$, the extracts reduced $\mathrm{H}_{2} \mathrm{O}_{2}$-induced oxidative stress in human lymphocytes and increased cell viability to more than $90 \%$ in MTT assay. The analyzed plants may also be valuable in the protection of platelets against oxidative stress and its consequent pathological platelet activation and aggregation. Therefore, S. altissima and S. alpina may represent promising new sources of compounds offering significant benefits in diseases typified by an imbalance between oxidative reactions and the antioxidant process. However, future studies should be extended to include other groups of compounds besides flavonoids, which can play a role in the antioxidant activity of Scutellaria extracts.

\section{References}

1. Shang X, He X, He X, et al. The genus Scutellaria an ethnopharmacological and phytochemical review. J Ethnopharmacol. 2010;128(2):279-313.

2. de Boer JG, Quiney B, Walter PB, et al. Protection against aflatoxin-B 1 -induced liver mutagenesis by Scutellaria baicalensis. Mutat Res. 2005;578(1):15-22.

3. Jang SI, Kim HJ, Hwang KM, et al. Hepatoprotective effect of baicalin, a major flavone from Scutellariae radix, on acetaminopheninduced liver injury in mice. Immunopharmacol Immonotoxicol. 2003;25(4):585-594.

4. Zhao Y, Li H, Gao Z, Gong Y, Xu H. Effects of flavonoids extracted from Scutellaria baicalensis Georgi on hemin-nitrite- $\mathrm{H}_{2} \mathrm{O}_{2}$ induced liver injury. Eur J Pharmacol. 2006;536(1):192-199.

5. Cheng Y, He G, Mu X, Zhang T. Neuroprotective effect of baicalein against MPTP neurotoxicity. Neurosci Lett. 2008;441(1):16-20.

6. Gao Z, Huang K, Yang X, Xu H. Free radical scavenging and antioxidant activities of flavonoids extracted from the radix of Scutellaria baicalensis Georgi. Biochim Biophys Acta. 199;1472(3):643-650.

7. Maresca M, Colao C, Leoncini G. Generation of hydrogen peroxide in resting and activated platelets. Cell Biochem Funct. 1992;10(2): 79-85.

8. Jahn B, Hänsch GM. Oxygen radical generation in human platelets: Dependence on 12-lipoxygenase activity and on the glutathione cycle. Int Arch Allergy Appl Immunol. 1990;93(1):73-79.

9. Blockmans D, Deckmyn H, Vermylen J. Platelet actuation. Blood Rev. 1995;9(3):143-156.

10. Jiang $H$, Chess $L$. An integrated view of suppressor $T$ cell subsets in immunoregulation. J Clin Invest. 2004;114(9):1198-1208.

11. Grzegorczyk-Karolak I, Wysokińska H, Olas B. Studies on the antioxidant properties of extracts from the roots and shoots of two Scutellaria species in human blood plasma Acta Biochim Pol. 2015;62(2):253-258.

12. Tutin T, Heywood H, Burges A, Valentine D, eds. Flora Europaea, vol 3. Cambridge, UK: Cambridge University Press; 1972.

13. Singleton VL, Rossi JA. Colorimetry of total phenolics with phosphomolybdic-phosphotungstic acid reagents. American Journal of Enology and Viticulture. 1965;16:144-158.

14. Walkowiak B, MichalakE, Koziołkiewicz W, Cierniewski CS. Rapid photometric method for estimation of platelet count in blood plasma or platelet suspension. Thromb Res. 1989;56(6):763-766.

15. Olas B, Żbikowska HM, Wachowicz B, Krajewski T, Buczyński A, Magnuszewska A. Inhibitory effect of resveratrol on free radical generation in blood platelets. Acta Biochim Pol. 1999;46(4):961-966.

16. Wachowicz B. Adenine nucleotides in thrombocytes of birds. Cell Biochem Funct. 1984;2(3):167-170.

17. Abe K, Matsuki N. Measurement of cellular 3-(4,5-dimethylthiazol-2-yl)-2,3-diphenyltetrazolium bromide (MTT) reduction activity and lactate dehydrogenase release using MTT. Neurosci Res. 2000;38(4):325-329.

18. Fotakis $G$, Timbrell JA. In vitro cytotoxicity assays: Comparison of LDH, neutral red, MTT and protein assay in hepatoma cell lines following exposure to cadmium chloride. Toxicol Lett. 2006;160(2):171-177.

19. Wu KK. Platelet activation mechanisms and markers in arterial thrombosis. J Intern Med. 1996;239(1):17-34.

20. Wachowicz B, Olas B, Żbikowska HM, Buczyński A. Generation of reactive oxygen species in blood platelets. Platelets. 2002;13(3):175-182.

21. Lee JJ, Kim T, Cho WK, Ma JY. Antithrombotic and antiplatelet activities of Soshiho-tang extract. BMC Complement Altern Med. 2013;13:137. 
22. Zhang $Y$, Wang $X$, Wang $X$, et al. Protective effect of flavonoids from Scutellaria baicalensis Georgi on cerebral ischemia injury. J Ethnopharmacol. 2006;108(3):355-360.

23. Olas B, Wachowicz B, Nowak P, et al. Studies on antioxidant properties of polyphenol-rich extract from berries of Aronia melanocarpa in blood platelets. Acta Physiol Pol. 2008;59:823-835.

24. Olas B, Wachowicz B. Resveratrol and vitamin $C$ as antioxidants in blood platelets. Thromb Res. 2002;106(2):143-148.

25. Kubo M, Matsuda H, Tani T, Arichi S, Kimura Y, Okuda H. Studies on Scutellariae radix. XII. Anti-thrombic actions of various flavonoids from Scutellariae radix. Chem Pharm Bull (Tokyo). 1985;33(6):2411-2415.

26. Zhang XW, Li WF, Li WW, et al. Protective effects of the aqueous extract of Scutellaria baicalensis against acrolein-induced oxidative stress in cultured human umbilical vein endothelial cells. Pharm Biol. 2011;49(3):256-261.

27. Shojaee $\mathrm{S}$, Parhiz H, Eshaghi A, et al. In vitro protective effects of Scutellaria litwinowii root extract against $\mathrm{H}_{2} \mathrm{O}_{2}$-induced DNA damage and cytotoxicity. J Complement Integr Med. 2014;11(2):121-127.

28. Porrini M, Riso P. Lymphocyte lycopene concentration and DNA protection from oxidative damage is increased in women after a short period of tomato consumption. J Nutr. 2000;130(2):189-192.

29. Böhm F, Tinkler, JH, Truscott TG. Carotenoids protect against cell membrane damage by nitrogen dioxide radical. Nat Med. 1995;1(2):98-99.

30. Lin $\mathrm{KH}$, Yang YY, Yang CM, et al. Antioxidant activity of herbaceous plant extracts protect against hydrogenperoxide-induced DNA damage in human lymphocytes. BMC Res Notes. 2013;6(1):490.
31. Pool-Zobel BL, Bub A, Müller H, Wollowski I, Rechkemmer G. Consumption of vegetables reduces genetic damage in humans: First results of a human intervention trial with carotenoid-rich foods. Carcinogenesis. 1997;18(9):1847-1850.

32. Lee TK, O'Brien KF, Wang W, et al. American ginseng modifies ${ }^{137} \mathrm{Cs}$-induced DNA damage and oxidative stress in human lymphocytes. Open Nucl Med J. 2009;1(1):1-8.

33. Grzegorczyk-Karolak I, Gołąb K, Gburek J, Wysokińska H, Matkowski A. Inhibition of advanced glycation end-product formation and antioxidant activity by extracts and polyphenols from Scutellaria alpina L. and S. altissima L. Molecules. 2016;21(6):739.

34. Grzegorczyk I, Matkowski A, Wysokińska H. Antioxidant activity of extracts from in vitro cultures of Salvia officinalis L. Food Chem. 2007;104:536-541.

35. Makowczyńska J, Grzegorczyk-Karolak I, Wysokińska H. Antioxidant activity of tissue culture-raised Ballota nigra L. plants grown ex vitro. Acta Pol Pharm. 2005;72(4):769-775.

36. Gu L, Weng X. Antioxidant activity and components of Salvia plebeia R. Br.: A Chinese herb. Food Chem. 2001;73:299-305.

37. Zhang KQ, Bao Y, Wu P, Rosen RT, Ho CT. Antioxidative components of tanshen (Salvia miltiorhiza Bunge). J Agric Food Chem. 1990;38:1194-1197.

38. Aruoma OI, Halliwell B, Aeschbach R, Löligers J. Antioxidant and prooxidant properties of active rosemary constituents: Carnosol and carnosic acid. Xenobiotica. 1992;22(2):257-268.

39. Bruno M, Piozzi F, Rodríguez B, Torre MC, Vassallo N, Servettaz O. Neo-clerodane diterpenoids from Scutellaria altissima and S. albida. Phytochemistry. 1996;42(4):1059-1064.

40. Malakov PY, Papanov GY. Neo-clerodane diterpenoids from Scutellaria alpina. Phytochemistry. 1998;49(5):2449-2452. 